\title{
Performance-Based Multiobjective Optimal Seismic Retrofit Method for a Steel Moment-Resisting Frame Considering the Life-Cycle Cost
}

\author{
Hyo Seon Park, ${ }^{1,2}$ Dong Chul Lee, ${ }^{3}$ Byung Kwan Oh, ${ }^{1,2}$ Se Woon Choi, ${ }^{4}$ and Yousok Kim ${ }^{2}$ \\ ${ }^{1}$ Department of Architectural Engineering, Yonsei University, 134 Shinchon-dong, Seoul 110-732, Republic of Korea \\ ${ }^{2}$ Center for Structural Health Care Technology in Buildings, Yonsei University, 134 Shinchon-dong, Seoul 110-732, Republic of Korea \\ ${ }^{3}$ Chang Minwoo Structural Consultants, 605-8 Yeoksam-Dong, Seoul 135-907, Republic of Korea \\ ${ }^{4}$ Department of Architecture, Catholic University of Daegu, 13-13 Hayang-ro, Hayang-eup, Gyeongsan-si, \\ Gyeongbuk 712-702, Republic of Korea
}

Correspondence should be addressed to Yousok Kim; yskim1220@yonsei.ac.kr

Received 17 September 2013; Revised 9 January 2014; Accepted 13 January 2014; Published 25 March 2014

Academic Editor: Pedro Ribeiro

Copyright (c) 2014 Hyo Seon Park et al. This is an open access article distributed under the Creative Commons Attribution License, which permits unrestricted use, distribution, and reproduction in any medium, provided the original work is properly cited.

This study proposes a performance-based multiobjective optimization seismic retrofit method for steel moment-resisting frames. The brittle joints of pre-Northridge steel moment-resisting frames are retrofitted to achieve ductility; the method involves determining the position and number of connections to be retrofitted. The optimal solution is determined by applying the nondominated sorting genetic algorithm-II (NSGA-II), which acts as a multiobjective seismic retrofit optimization technique. As objective functions, the initial cost for the connection retrofit and lifetime seismic damage cost were selected, and a seismic performance level below the $5 \%$ interstory drift ratio was employed as a constraint condition. The proposed method was applied to the SAC benchmark three- and nine-story buildings, and several Pareto solutions were obtained. The optimized retrofit solutions indicated that the lifetime seismic damage cost decreased as the initial retrofit cost increased. Although every Pareto solution existed within a seismic performance boundary set by a constraint function, the seismic performance tended to increase with the initial retrofit cost. Analysis and economic assessment of the relations among the initial retrofit cost, lifetime seismic damage cost, total cost, and seismic performance of the derived Pareto solution allow building owners to make seismic retrofit decisions more rationally.

\section{Introduction}

In 1994, the Northridge earthquake caused the unexpected brittle fracture of connections on steel moment-resisting frames (SMRFs) that resulted in a considerable loss of life and enormous economic damage. Since then, studies on the seismic performance of SMRF connections and seismic retrofits have been actively conducted. The seismic retrofit of a SMRF is generally achieved by reinforcing connections and installing buckling-restrained braces (BRBs) to increase strength and ductility and by installing dampers and seismic isolation devices to decrease the earthquake force.

Studies on the seismic retrofit of existing buildings with these retrofit methods have been actively conducted based on performance-based seismic engineering, as in the seismic design field. Hussain et al. [1] and Ash and Bartoletti [2] presented seismic retrofit schemes that use dampers and BRBs, respectively. They applied these proposed seismic retrofit schemes to existing buildings and verified that performance objectives were met through a performance assessment of buildings. Liu et al. [3] proposed seismic retrofit schemes that combine dampers and BRBs. Malley et al. [4] suggested seismic retrofit schemes that combine connection upgrade and dampers. They also verified that these retrofit schemes meet the performance objectives of buildings. However, in these studies, more suitable retrofit schemes were selected through a conventional trial-error method or by assessing the performance of several alternatives; a clear standard and rational basis was not followed. 
Optimal seismic retrofit studies have applied optimization techniques to overcome the limitations of the above studies. Aydin and Boduroglu [5] proposed a seismic retrofit method that determines the appropriate placement and size of the cross-section of braces based on optimization techniques. However, this method only minimizes structural responses, such as the roof displacement and base shear, by setting these responses to an objective function; it does not consider the economic feasibility of the retrofit. Hagishita and Ohsaki [6] presented a retrofit scheme that minimizes the volume and placement of braces satisfying story drift and strength constraint conditions using the scatter search method, which is an optimization technique. Although the economic feasibility is considered by setting the volume to be an objective function, the method is not considered performance-based seismic retrofitting. Oh [7] presented an optimal seismic retrofit model that combines performancebased seismic engineering and a genetic algorithm (GA), which is an optimization technique. The study suggested a seismic retrofit method that minimizes the retrofit cost by minimizing the number of connections to be upgraded (retrofitted) and presents the optimal placement satisfying the given performance objectives.

In earthquake engineering, the life-cycle cost is assessed by the initial costs and lifetime seismic damage costs for earthquakes that might occur during the structure's life cycle. In general, buildings that are designed and retrofitted to maintain high performance against earthquakes incur high initial costs. However, the probability of damage due to an earthquake decreases along with the lifetime seismic damage cost. In contrast, designs and retrofits with low performance levels against earthquakes generate low initial costs. However, the lifetime seismic damage cost increases with the probability of damage due to an earthquake. Thus, a rational economic assessment should consider both the initial cost and lifetime seismic damage cost that might be incurred during the life cycle to provide the optimal design in terms of effective economic feasibility.

Studies that assess the economic feasibility of seismic designs by considering the life-cycle cost are actively in progress. Kang and Wen [8] evaluated the lifetime seismic damage cost caused by an earthquake for steel-frame structures based on FEMA227 data. They presented a method to determine the design strength of the structure that minimizes the sum of the initial cost and lifetime seismic damage cost. Kohno and Collins [9] used HAZUS to assess the damage costs caused by an earthquake and presented an optimal design that minimizes the life-cycle cost. However, these studies selected and proposed the most appropriate design among several design schemes through various analysis processes using conventional trial-and-error methods, not an optimization technique.

Liu et al. [10, 11] proposed a multiobjective optimal seismic design that uses GA to solve an objective function that considers the initial cost, lifetime seismic damage cost, and design complexity. Fragiadakis et al. [12] developed a multiobjective optimal seismic design that uses a structure's weight and life-cycle cost as the objective function and is based on an evolutionary algorithm (EA). As an important factor for assessing the economic feasibility, the life-cycle cost is considered when determining design schemes in the seismic design field.

Studies $[13,14]$ on seismic retrofits have considered the life-cycle cost to assess the rational economic feasibility. These studies presented seismic retrofit schemes for bridges and infrastructures based on the life-cycle costs. As mentioned above, Oh's [11] seismic retrofit study did not consider a rational assessment of the economic feasibility for retrofit schemes represented in his study because it ignored the lifetime seismic damage cost that can occur during the life cycle and limited the economic feasibility assessment to the initial cost, that is, the number of connections retrofitted. To the best of our knowledge, optimization techniques that consider the life-cycle costs (i.e., both the initial retrofit cost and life-cycle cost) have not yet been applied to performancebased seismic retrofitting.

The present paper proposes a performance-based multiobjective optimization seismic retrofit method that uses the nondominated sorting genetic algorithm-II (NSGA-II) optimization technique as a multiobjective GA for rational and economic seismic retrofitting. For the objective functions, the cost involves not only the initial retrofit cost but also the life-cycle cost after retrofit to assess the rational economic feasibility. For the life-cycle cost assessment after retrofit, the lifetime seismic damage cost is assessed according to a probabilistic model that is used in the seismic design. In this study, among various seismic retrofit methods, retrofit that makes brittle connections behave in a ductile manner was considered. The optimal location and number of connection upgrades are determined within a range that satisfies the given performance objective, which is employed as a constraint condition in the optimization technique. The proposed method was applied to SAC benchmark three- and nine-story steel moment-resisting frames, and its usefulness was verified from the obtained optimized retrofit solutions.

\section{Life-Cycle Cost for Seismic Retrofit}

2.1. Initial Retrofit Cost Calculation. The initial cost of the lifecycle cost in seismic design refers to the initial design cost, that is, the initial structure volume. Similarly, the initial cost in seismic retrofitting also refers to the initial retrofit cost. In this study, the selected seismic retrofit method involves directly retrofitting the brittle connections of existing steel moment-resisting frames so that they behave in a ductile manner. FEMA351 [15] and AISC/NIST Design Guide 12 [16] present design methods and connection details for improved ductile capacity and plastic rotation capacity of connections over existing brittle connections; these include prequalified connection upgrades, such as a welded bottom haunch $(\mathrm{WBH})$, welded top and bottom haunch (WTBH), and welded cover plate flange (WCF), and proprietary connection retrofit methods, such as a bolted bracket (BB), slotted web connection (SW), and side plate connection (SP). The retrofitted connections were experimentally verified to improve seismic performance [17-19]. In this study, the selected retrofit method used haunches, as shown in Figure 1 [17]. 


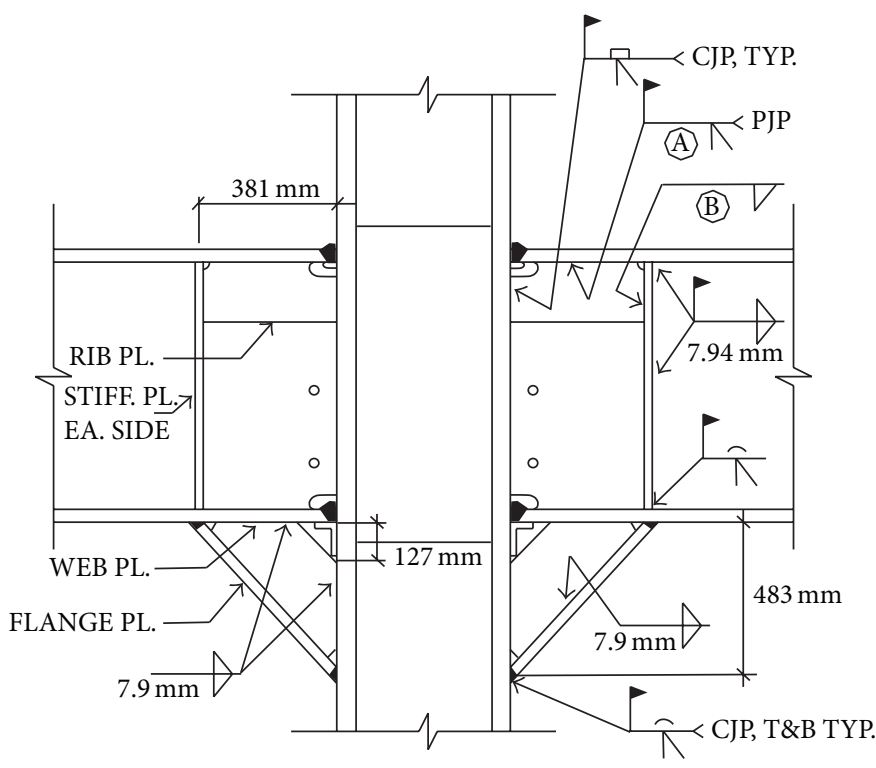

FIGURE 1: Details of the retrofitted connection by a welded haunch.

In this case, the initial cost mainly consists of the material costs for the structural steel used to retrofit the connections and includes the welding, wages, and other items needed for construction. FEMA351 [15] presents a connection restoration cost function through existing retrofit cases and cost analysis. Based on this function, the connection unit cost can be determined relatively simply as 20,000 USD. This value includes the cost for partial demolition of the target building and restoration and reinforcement of the finished building and utilities for access to retrofit.

This paper proposes seismic retrofit schemes for retrofitting the connections of an existing steel moment-resisting frame. These seismic retrofit schemes present the location and number of connections being retrofitted out of all of the frame's connections. The cost of each seismic retrofit proposal is calculated according to the number of retrofitted connections. In other words, the seismic retrofit cost is directly determined by multiplying the number of connections being reinforced and the retrofit cost per connection.

2.2. Calculation of Lifetime Seismic Damage Costs. This study employed the method used by Kang and Wen [8], Liu et al. $[10,11]$, and Fragiadakis et al. [12] to assess the lifetime seismic damage cost that occurs during the life cycle of a steel building being retrofitted. The lifetime seismic damage cost comprises the annual occurrence probability of the damage states being considered, the sum of the product of the cost function multiplied by the damage state and discount rate, and the building's life cycle. The assessment calculation formula is as follows:

$$
E[C(t, X)]=\frac{v}{\lambda}\left(1-e^{-\lambda t}\right) \sum_{j=1}^{K} C_{j} P_{j} .
$$

Here, $K$ is the number of seismic damage states that are considered, and the damage index that describes the seismic
TABLE 1: Performance level and damage state in terms of the interstory drift ratios.

\begin{tabular}{lcc}
\hline Performance level & Damage state & Interstory drift ratios (\%) \\
\hline I & None & $\Delta<0.2$ \\
II & Slight & $0.2<\Delta<0.5$ \\
III & Light & $0.5<\Delta<0.7$ \\
IV & Moderate & $0.7<\Delta<1.5$ \\
V & Heavy & $1.5<\Delta<2.5$ \\
VI & Major & $2.5<\Delta<5.0$ \\
VII & Destroyed & $5.0<\Delta$ \\
\hline
\end{tabular}

damage state that occurs in the steel moment-resisting frame due to the predicted earthquake was defined as the maximum interstory drift rate (Table 1 ). $\lambda$ is the annual monetary discount rate, $t$ is the service life of the building, and $v$ is the annual occurrence rate for the relevant seismic damage state and is defined by the Poisson process. $P_{j}$ is the damage state occurrence probability of the annual $j$ th seismic damage state, and $C_{j}$ is the damage cost that occurs at the $j$ th seismic damage state. In case $\Delta_{j, \text { min }}$ and $\Delta_{j, \max }$ are the ranges of the maximum story drift ratio, which is the damage index relevant to the $j$ th seismic damage state, $P_{j}$ can be described as follows:

$$
P_{j}=P\left(\Delta>\Delta_{j, \min }\right)-P\left(\Delta>\Delta_{j, \max }\right) .
$$

Here, $P\left(\Delta>\Delta_{j, \min }\right)$ and $P\left(\Delta>\Delta_{j, \max }\right)$ are equivalent to the annual probabilities that the story drift ratio will exceed the maximum story drift ratios $\Delta_{j, \min }$ and $\Delta_{j, \max }$, respectively; these probabilities can be found by using $P_{t}(\Delta>$ $\left.\Delta_{j, \text { min }}\right)$ and $P_{t}\left(\Delta>\Delta_{j, \max }\right) . P_{t}\left(\Delta>\Delta_{j, \min }\right)$ and $P_{t}(\Delta>$ $\left.\Delta_{j, \max }\right)$ are the probabilities that the maximum story drift 
rates $\Delta_{j \text {,min }}$ and $\Delta_{j \text {,max }}$ will be exceeded within $t$ years, as expressed below:

$$
\begin{aligned}
& P\left(\Delta>\Delta_{j, \text { min }}\right)=-\frac{1}{v \times t}\left\{\ln \left[1-P_{t}\left(\Delta>\Delta_{j, \text { min }}\right)\right]\right\}, \\
& P\left(\Delta>\Delta_{j, \text { max }}\right)=-\frac{1}{v \times t}\left\{\ln \left[1-P_{t}\left(\Delta>\Delta_{j, \text { max }}\right)\right]\right\} .
\end{aligned}
$$

To calculate $P_{t}\left(\Delta>\Delta_{j, \min }\right)$ and $P_{t}\left(\Delta>\Delta_{j, \max }\right)$, three seismic damage states having $50 \%, 10 \%$, and $2 \%$ exceedance probabilities in 50-year earthquakes are considered. A structural analysis (nonlinear static analysis) is used to determine the interstory drift ratio of each case and the exceedance probability for each seismic damage state. These results are used in a regression analysis to find the annual exceedance probability. In the regression analysis, the annual exceedance probability assumes a generalized extreme value distribution (GEVD) as a probabilistic distribution, and the regression analysis is performed using the least-squares method.

$C_{j}$ is described in Formula (4) and consists of the following six terms: direct structural and nonstructural damage and repair cost $\left(C_{j}^{\text {dam }}\right.$; damage cost $)$, equipment/facility restoration cost $\left(C_{j}^{\text {con }}\right.$; loss of contents), relocation cost according to the function loss of the facility $\left(C_{j}^{\text {rel }}\right.$; relocation cost $)$, economic loss ( $C_{j}^{\mathrm{eco}}$; economic loss), monetary value equivalent to the injury ( $C_{j}^{\text {inj }}$; cost of injury), and monetary value equivalent to death $\left(C_{j}^{\mathrm{fat}}\right.$; cost of human fatality). Consider

$$
C_{j}=C_{j}^{\mathrm{dam}}+C_{j}^{\mathrm{con}}+C_{j}^{\mathrm{rel}}+C_{j}^{\mathrm{eco}}+C_{j}^{\mathrm{inj}}+C_{j}^{\mathrm{fat}} .
$$

\section{NSGA-II Based Optimal Retrofit Method}

This study determined the location and number of connection upgrades that minimize the initial connection retrofit cost (initial installation cost) and the lifetime seismic damage cost during the life cycle after retrofit while meeting the required seismic performance level. The objective functions were set to minimize not only the number of initial connection retrofits but also the lifetime seismic damage cost during the life cycle after retrofit, and an interstory drift ratio representing the structural performance was employed as a constraint condition. The NSGA-II [20], which is a multiobjective optimizing technique, was used to find the optimal solution.

3.1. Objective Functions. Optimization problems generally have a single objective function. However, there are occasionally cases in which more than two conflicting objective functions should be considered simultaneously. Multiobjective optimization techniques are applied to solve these problems $[11,12,21]$.

In this study, the problems of minimizing both the initial seismic retrofit cost and lifetime seismic damage cost were considered; these are two conflicting targets. Thus, the multiobjective optimization technique was applied to minimize not only the initial retrofit cost but also the life-cycle cost. The heuristic-based GA $[22,23]$ has a relatively simple theory and high applicability in various fields. In structure optimization, the GA is applied to optimize the structure volume, crosssectional shape, and reinforcement techniques. While the classic GA must be executed many times to find several Pareto optimal solutions, the multiobjective GA can find several Pareto optimal solutions in a single execution. NSGA-II [20], which is a Pareto-based optimization technique, was used in this study to find a set of optimal retrofit schemes.

The first objective function is the initial cost for the connection retrofit. In general, the seismic retrofit cost for the connection retrofit of a steel moment-resisting frame is calculated by multiplying the number of retrofitted connections by the retrofit cost for a single connection. Consequently, the initial cost is directly correlated to the number of connections being retrofitted, and minimizing the number of connections being retrofitted minimizes the initial costs. Consider

$$
\text { Minimize } F_{1}(X)=\sum_{i=1}^{n} X_{i}
$$

Here, $X_{i}$ is the design variable of the optimization algorithm in this study and indicates whether the $i$ th connection has been retrofitted. If $X_{i}=1$, retrofit has been provided to the $i$ th connection; the retrofitted connection is modeled as hysteresis behavior with sufficient ductile capacity. If $X_{i}=0$, the $i$ th connection is modeled as hysteresis behavior where early brittle fracture occurs; it means that retrofit has not been provided. $N$ is the number of connections included in the SMRF.

The second objective function minimizes the lifetime seismic damage cost that can occur after retrofit, as noted in Section 2.2; it is formulated below:

$$
\text { Minimize } F_{2}(X)=\frac{\nu}{\lambda}\left(1-e^{-\lambda t}\right) \sum_{j=1}^{K} C_{j} P_{j} \text {. }
$$

Here, Formula (6) is described in Section 2.2. In this study, the annual discount rate $\lambda$ was set to 0.05 , and the service life of the building $t$ was set to 50 years.

3.2. Constraint Condition. FEMA 356 [24] presents a seismic design method to set the performance objective for the structure to evaluate the seismic performance. The performance objective is an indicator to determine the performance level that the target structure can endure at a specific scaled earthquake. The performance level is set by quantifying the structure's displacement, and the structure is designed to achieve the performance objective. This entire process is called the performance-based seismic design concept. The performance objective is determined by the specific performance level, such as the level of operation and damage occurred due to an earthquake with respect to the specific earthquake hazard level defined by the exceedance probability for the recurrence period. In this study, seismic retrofitting was performed to meet performance objective $P$ presented in FEMA 356; this is the performance level of collapse prevention (CP) from a very rare earthquake hazard level (2\%/50 years) [24]. FEMA 356 defines the performance level to prevent collapse of the steel moment-resisting frame as the maximum interstory drift 


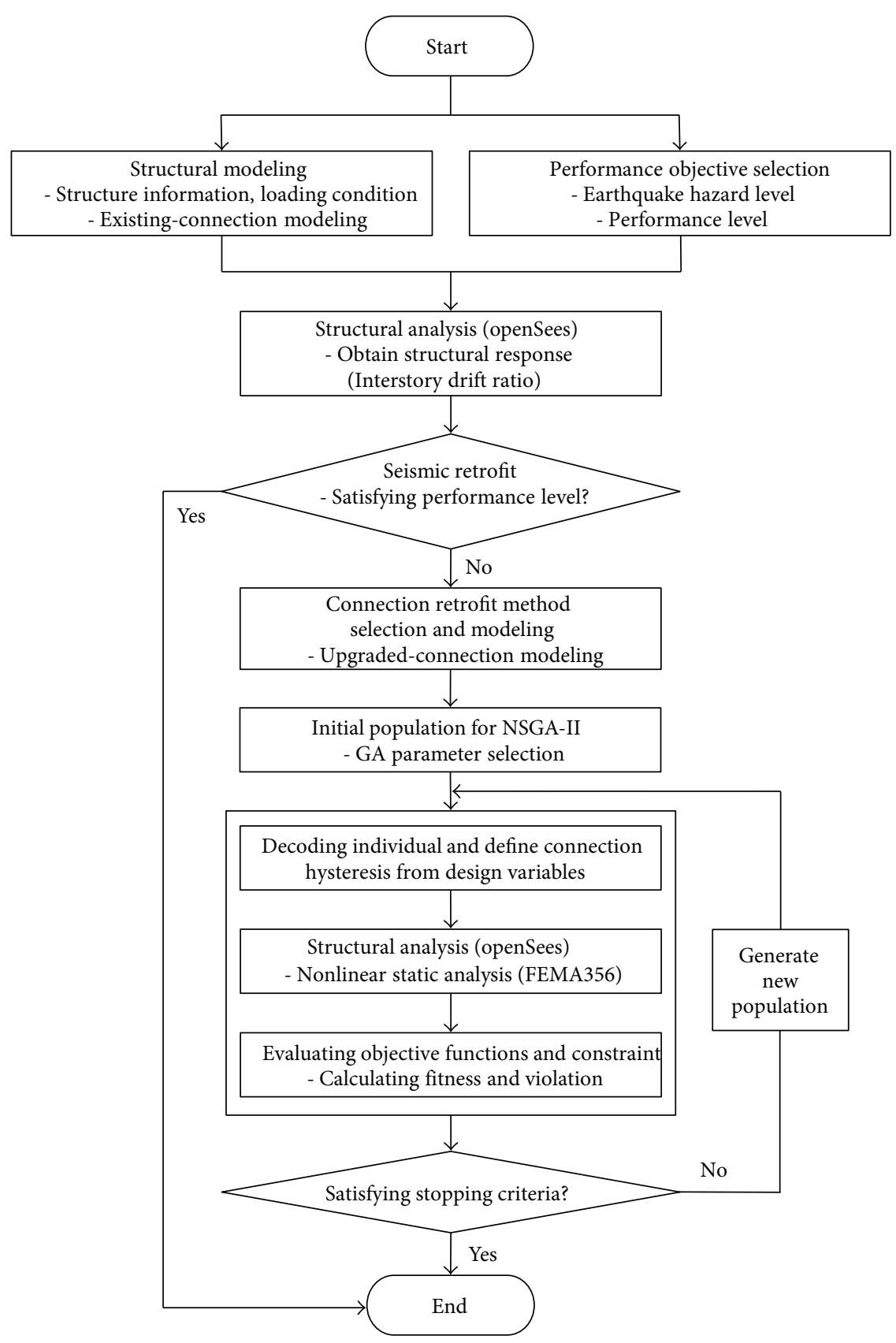

FIGURE 2: Flowchart for the multiobjective seismic retrofit method.

ratio, which is $5 \%$. Consequently, the allowable interstory drift ratio is set as the constraint function and is determined by

$$
\text { s.t. } \frac{\Delta^{\max }}{\Delta_{a}}<1
$$

Here, $\Delta_{a}$ is the allowable interstory drift ratio and $\Delta^{\max }$ is the maximum interstory drift ratio that is calculated by the nonlinear static analysis for a building modeled in OpenSees and is calculated by

$$
\Delta^{\max }=\max \left(\frac{\delta^{i+1}-\delta^{i}}{h^{i}}\right), \quad i=1, n .
$$

In (8), $\delta^{i}$ is the drift on the $i$ th floor, and $h^{i}$ is the height of the $i$ th floor.

Finally, Figure 2 presents a flowchart of the proposed multiobjective seismic retrofit method described above.

\section{Applications}

The proposed performance-based optimization seismic retrofit method considering the life-cycle cost was applied to the SAC benchmark three- and nine-story examples. This benchmark model has been applied to many previous studies $[18,25,26]$. The example models were pre-Northridge steel moment-resisting frames and behaved with brittle fracture 


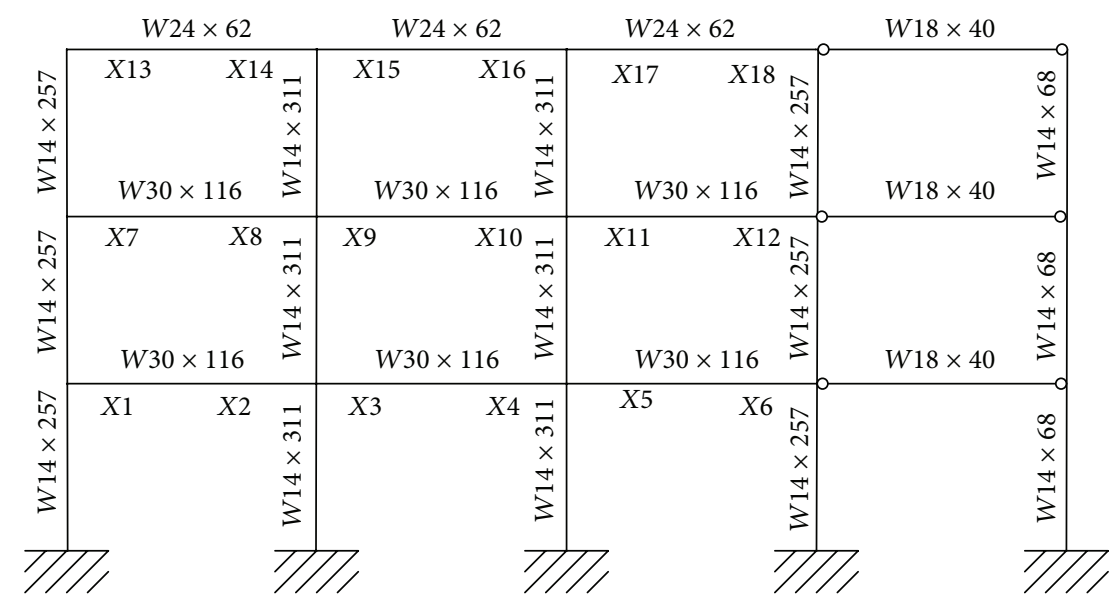

FIGURE 3: Three-story SMRF example.

prior to seismic retrofitting. The example models were assumed to be located in Los Angeles, CA, USA; the site class was $\mathrm{D}$, and the importance factor of the building was 1.0. The beams and columns were made from A36 and A572 Grade 50 steel, respectively.

4.1. Target Structures. The three-story steel moment-resisting frame used in this study is illustrated in Figure 3. The first three spans are a moment-resisting frame with preNorthridge connections, and the fourth span is a simple beam-column connection. Information on the structural members of the three-story frame is provided in Figure 3; the plan and detailed information were given by Shi [25]. The 18 connections are the targets of the retrofit and the design variables in the optimization process.

Figure 4 presents a nine-story steel-frame momentresisting frame with five spans and the information on the structural members of the nine-story example. The floor plan and other details are also found in Shi [25]. There are 90 connections in total; these connections are the subjects for the seismic retrofit and are used as the design variables in the optimization process.

4.2. Connection Modeling. Investigation of the buildings that were damaged by the Northridge earthquake in 1994 verified that an unexpected brittle fracture occurred. Afterwards, SAC Joint Venture performed experiments on the moment connections where early brittle fractures occurred. The hysteresis behavior characteristics of the brittle connections were verified $[27,28]$.

The connection seismic behavior before and after the connection upgrade should be defined in the analytical model to assess the performance of the steel moment-resisting frame before and after the retrofit. In this study, the structural behaviors of target structures are modeled and analyzed by OpenSees [29]. The nonlinear behaviors of structural members such as panel zone, column, and beam are modeled by Krawinkler's model [29, 30], beamWithHinges [29], and zero-length element [29], respectively. Table 2 shows the material properties used in the analytical modeling.
TABLE 2: Material properties for steel members (unit: ksi).

\begin{tabular}{lccc}
\hline & Panel & Column & Beam \\
\hline Elastic modulus & 29000 & 29000 & 29000 \\
Shear modulus & 11514 & 11514 & 11514 \\
Yield strength & 57.6 & $57.6 x$ & 49.2 \\
\hline
\end{tabular}

As for modeling of the panel zone, the Krawinkler model was used for the full dimension of the panel zone as shown in Figure 5. This model directly models a joint panel zone with rigid links and controls the deformation of the panel zone. The nonlinear behavior of the panel zone was modeled by rotational spring, where "hysteretic material" model in OpenSees was applied. The skeleton curve for determining the strength and rigidity of the panel zone was determined by combining two bilinear springs which represent the behaviors of the column web and flange, respectively (Figure 6). Formulas (9) are the equations for determining the skeleton curve for these bilinear springs:

$$
\begin{gathered}
\gamma_{y}=\frac{F_{y}}{\sqrt{3} G}, \\
\gamma_{P}=4 \gamma_{y}, \\
V_{y}=0.55 F_{y} d_{c} t \\
V_{p}=V_{y}\left(1+\frac{3 b_{c} t_{c f}^{2}}{d_{b} d_{c} t}\right) .
\end{gathered}
$$

Here, $F_{y}$ denotes the panel zone's yield strength, $G$ is the transverse modulus, $\gamma_{y}$ is the yield rotation angle, $\gamma_{p}$ is the perfect plastic rotation angle, $d_{c}$ is the depth of the column, $t$ is the panel zone thickness, $d_{b}$ is the depth of the beam, and $t_{c f}$ is the column flange thickness.

As for columns connected to the panel zone as shown in Figure 5, the "beamWithHinges" element in OpenSees was applied to simulate the nonlinear behavior of columns. This element divides the column into three parts: two hinges at the column ends and a linear-elastic region in the middle 


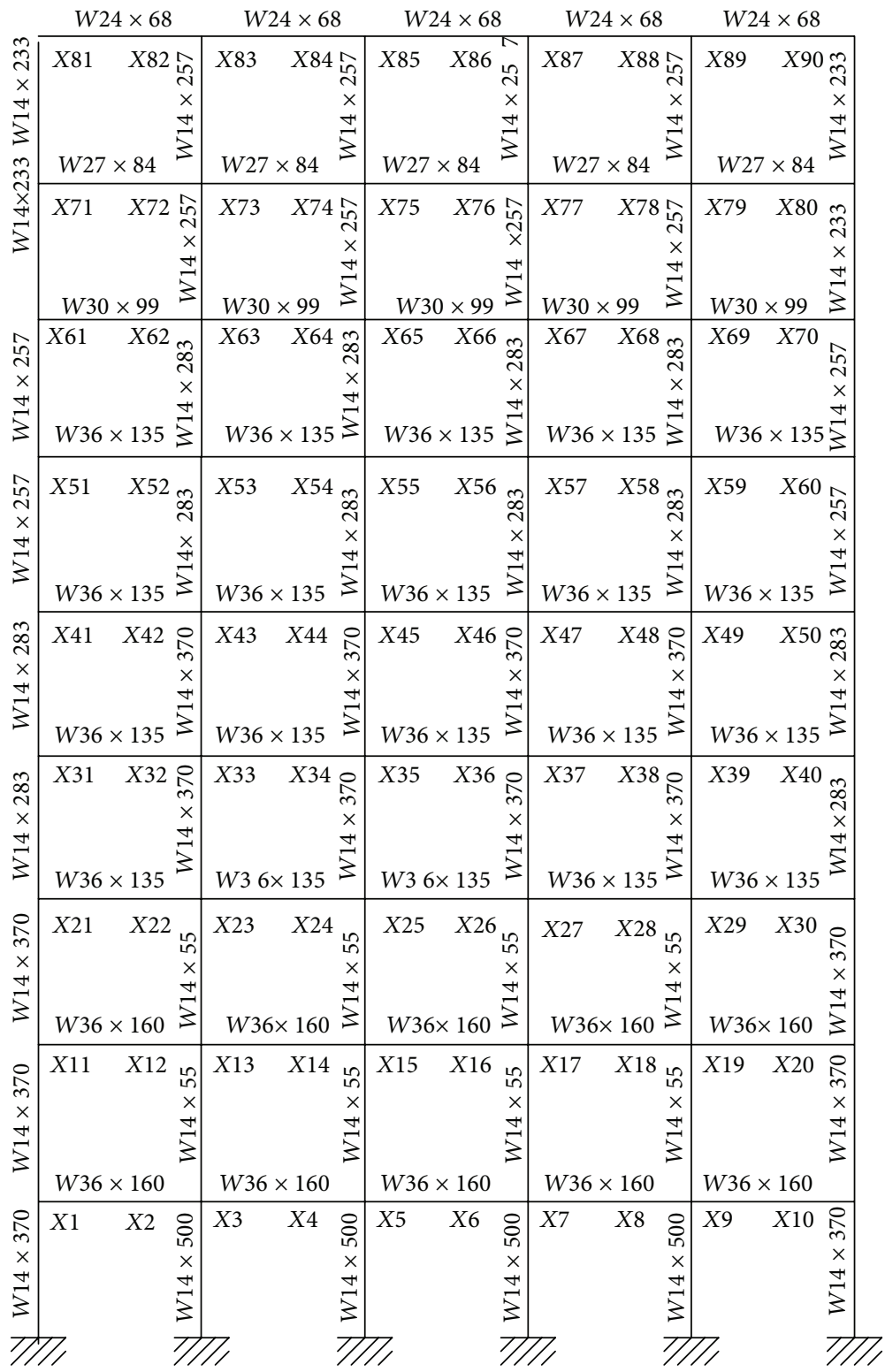

FIgURE 4: Nine-story SMRF example.

(Figure 7(a)). Furthermore, the beamWithHinges element used in this study has four elastic sections in the middle and two fiber section at each end. The hinges are defined by assigning to each a previously defined fiber section (Figure 7(b)). And the "Steel 01" model in OpenSees was applied to the material model for the nonlinear behavior of each fiber section (Figure 7(c)). Therefore, this element considers plasticity to be concentrated over specified hinge length at the column ends.

Finally, the zero-length elements were used to represent the hysteresis behavior of the beam connection's spring elements; the hysteresis behavior that characterized the brittle fracture and ductility capacity of the connection before and after the retrofit was reflected in the connection (rotational spring for the beam in Figure 5) modeling, as shown in Figure 8. Therefore, the effectiveness of retrofit, which can be evaluated by the different behaviors between before and after retrofit, was simulated from the zero-length element applied to the connections between panel zone and beam ends. In this study, a typical brittle hysteresis curve, such as in Figure 8(a) [27], was used to model the connection behavior before the retrofit of the steel moment-resisting frame. A sudden brittle fracture occurred at a rotation angle of $0.01 \mathrm{rad}$; after brittle fracture, the connection was modeled to have $20 \%$ [31] of the initial strength (My) without strength and rigidity degradation until $0.04 \mathrm{rad}$. As shown in Figure 8(b) $[15,32,33]$, a general type of ductile hysteresis curve was used to model the connection behavior after retrofit. The connection could reach a rotational angle of $0.04 \mathrm{rad}$ without strength degradation and was modeled to have $20 \%$ of the initial strength $(\mathrm{Mp})$ after fracture at $0.04 \mathrm{rad}$. 


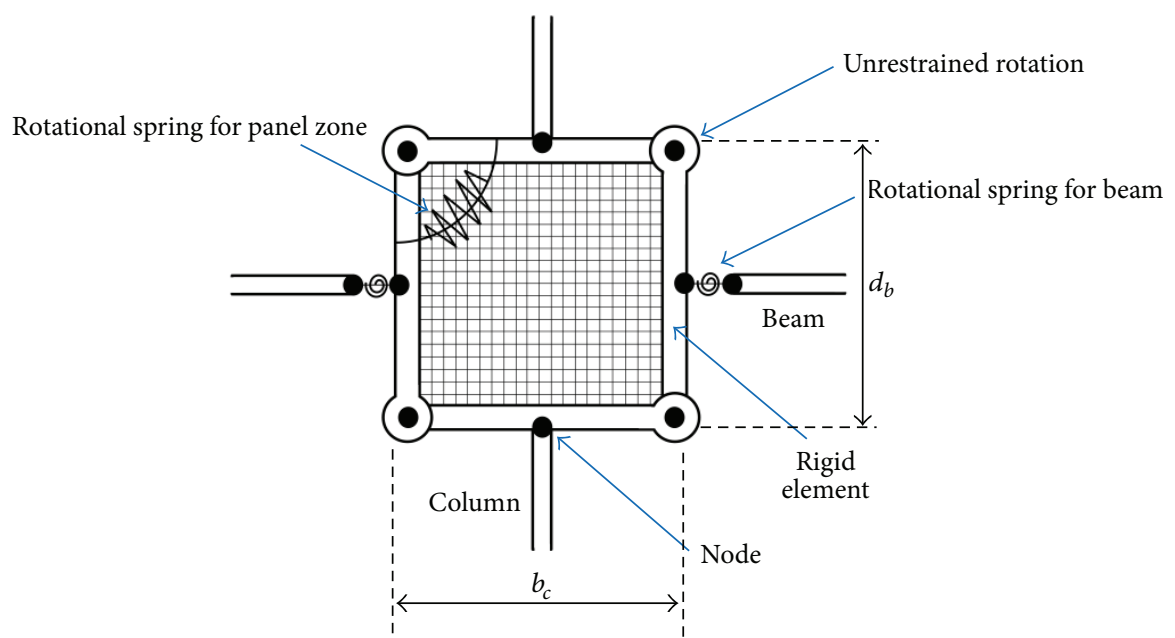

FIGURE 5: Beam-column joint model (Krawinkler's model).

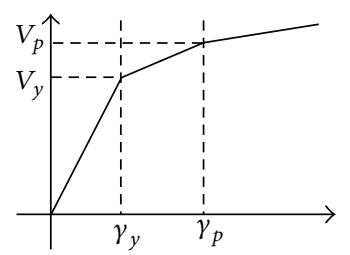

(a) Hysteretic material model

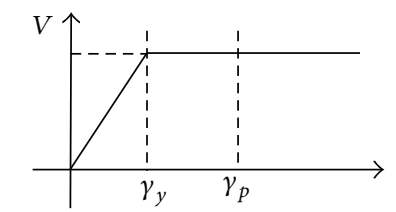

(b) Elastic-perfectly plastic

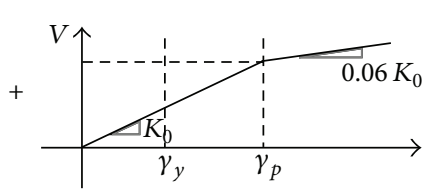

(c) Bilinear

FIgURE 6: Hysteretic model for panel zone.

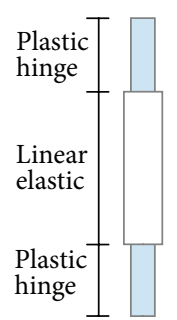

(a) beamWith-

Hinges

model

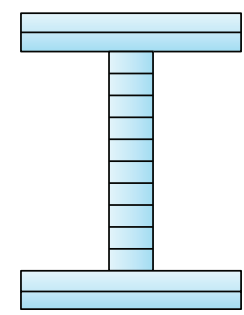

(b) Fiber section

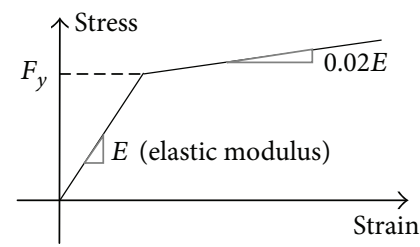

(c) Material model

Figure 7: Column model.

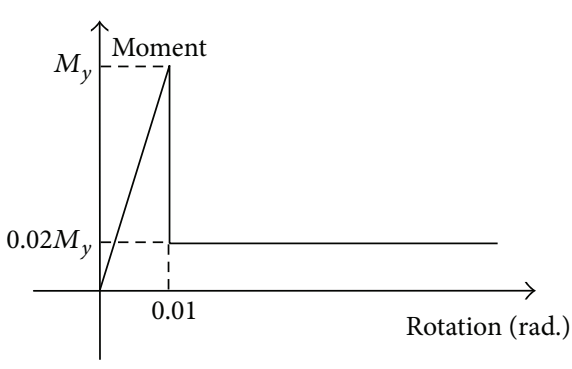

(a) Brittle connection

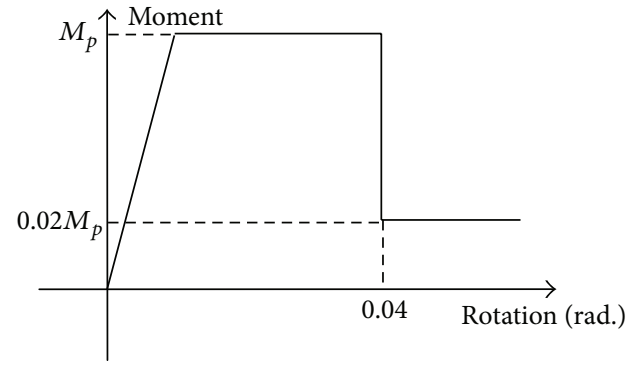

(b) Retrofitted connection

FIGURE 8: Hysteretic model for the rotational spring in a beam. 
TABLE 3: Optimal retrofit scheme of the three-story SMRF for performance objective $P$.

\begin{tabular}{|c|c|c|c|c|c|c|c|}
\hline & Before & Scheme 1 & Scheme 2 & Scheme 3 & Scheme 4 & Scheme 5 & Scheme 6 \\
\hline $\begin{array}{l}\text { Number of retrofit } \\
\text { connections }\end{array}$ & 0 & 4 & 6 & 7 & 8 & 10 & 12 \\
\hline Retrofit location & - & $\begin{array}{l}\text { X9-10 } \\
\text { X14 } \\
\text { X17 }\end{array}$ & $\begin{array}{c}\text { X6 } \\
\text { X9-10 } \\
\text { X15 } \\
\text { X17-18 }\end{array}$ & $\begin{array}{c}\text { X7 } \\
\text { X9-11 } \\
\text { X15-16 } \\
\text { X18 }\end{array}$ & $\begin{array}{c}\mathrm{X} 2 \\
\mathrm{X} 7-8 \\
\mathrm{X} 11-14 \\
\mathrm{X} 16\end{array}$ & $\begin{array}{c}\text { X4-7. X9-10 } \\
\text { X12-13 } \\
\text { X15-16 }\end{array}$ & $\begin{array}{c}\mathrm{X} 1 \\
\mathrm{X} 7-14 \\
\mathrm{X} 16-18\end{array}$ \\
\hline $\begin{array}{l}\text { Initial retrofit cost } \\
\text { (thousand dollars) }\end{array}$ & 0 & 80 & 120 & 140 & 160 & 200 & 240 \\
\hline $\begin{array}{l}\text { Lifetime seismic } \\
\text { damage cost } \\
\text { (thousand dollars) }\end{array}$ & 475 & 343 & 326 & 300 & 295 & 290 & 284 \\
\hline $\begin{array}{l}\text { Maximum interstory } \\
\text { drift ratio (\%) }\end{array}$ & 5.27 & 4.95 & 4.91 & 4.51 & 4.50 & 4.46 & 4.20 \\
\hline $\begin{array}{l}\text { Dissipated energy } \\
(\mathrm{kN} \cdot \mathrm{m})\end{array}$ & $1,157.22$ & $1,422.50$ & $1,496.26$ & $1,493.70$ & $1,613.64$ & $1,566.38$ & $1,561.35$ \\
\hline
\end{tabular}

\section{Results and Discussion}

5.1. Three-Story Building. In this example, among the performance objectives presented by FEMA 356, $P$ is selected, and the seismic performance of this example is evaluated for this performance objective. $P$ refers to the performance level of collapse prevention to very rare earthquakes. As shown in Figure 9, evaluating the seismic performance of the threestory example for $P$ yields a maximum interstory drift ratio of $5.27 \%$. This value exceeds the allowable interstory drift ratio of 5\% in FEMA 356 for CP. Seismic retrofitting is needed to achieve the given performance objective. Consequently, the proposed multiobjective optimization seismic retrofit method is applied to the example.

Six Pareto solutions, which are the optimal solutions, were obtained through NSGA-II. Table 3 summarizes the location and number of connections to be retrofitted, the initial retrofit cost, and the lifetime seismic damage cost of each Pareto solution.

The initial retrofit cost was calculated by multiplying the number of retrofits by the retrofit cost for a single connection. The unit retrofit cost of 20,000 USD suggested by FEMA 351 was applied. The interstory drift for each retrofit scheme is shown in Figure 9. All six retrofit proposals satisfied the allowable interstory drift ratio of $5 \%$ for $P$, which is employed as a constraint condition in this optimization technique.

Figure 10 presents the relationships between the initial retrofit cost, lifetime seismic damage cost, and seismic performance (interstory drift ratio) of the six Pareto solutions. In general, as the initial retrofit cost increases, the structural performance, which is represented by the interstory drift ratio, is improved (i.e., small interstory drift ratio), but the lifetime seismic damage cost decreases; the initial cost is inversely proportional to the lifetime seismic damage cost (Figure 11(a)). From these results, we can observe a trade-off between the initial retrofit cost and structural performance (interstory drift ratio), as is observed in the other general retrofit methods. However, an advantage of the proposed retrofit optimization scheme is that the decision maker

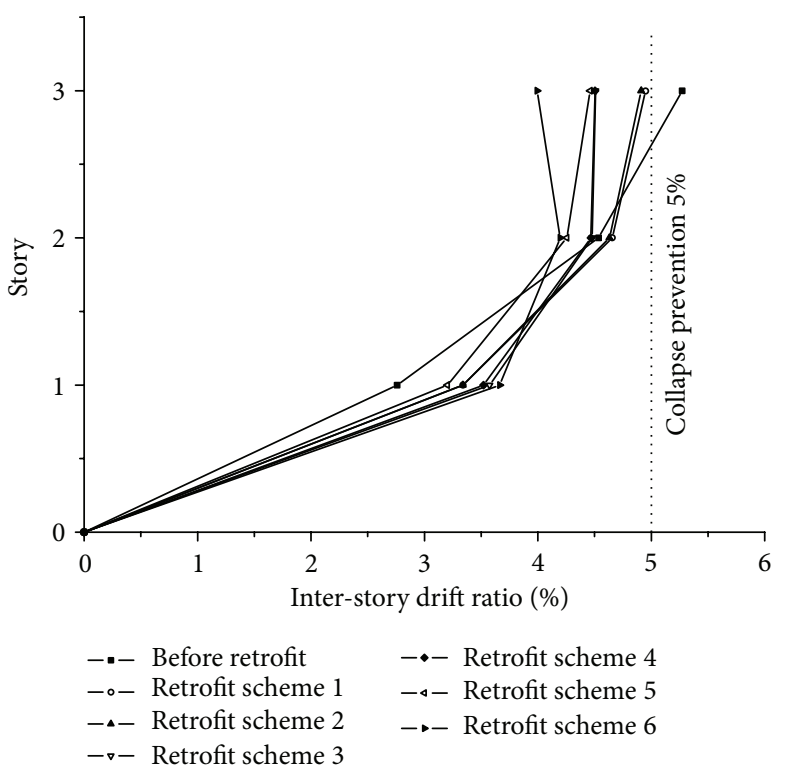

FIGURE 9: Interstory drift ratios of the existing and retrofitted threestory SMRF.

can select the retrofit strategy based on each cost (e.g., initial cost, lifetime seismic damage cost, and total cost) and structural performance (or structural safety); that is, a high initial cost results in low lifetime seismic damage cost and high structural performance, and a low initial cost results in high life-cycle seismic damage cost and low structural performance.

In terms of the total cost, which is the sum of the initial and lifetime seismic damage costs, the structural performance (interstory drift ratio) improves as the total cost increases (Figure 10). That is, as shown in Figure 11(b), the total cost is generally proportional to the initial cost in this example because the seismic retrofit unit cost (20,000 USD) is relatively high compared to the lifetime seismic damage cost. However, it can be expected that the relationship between 


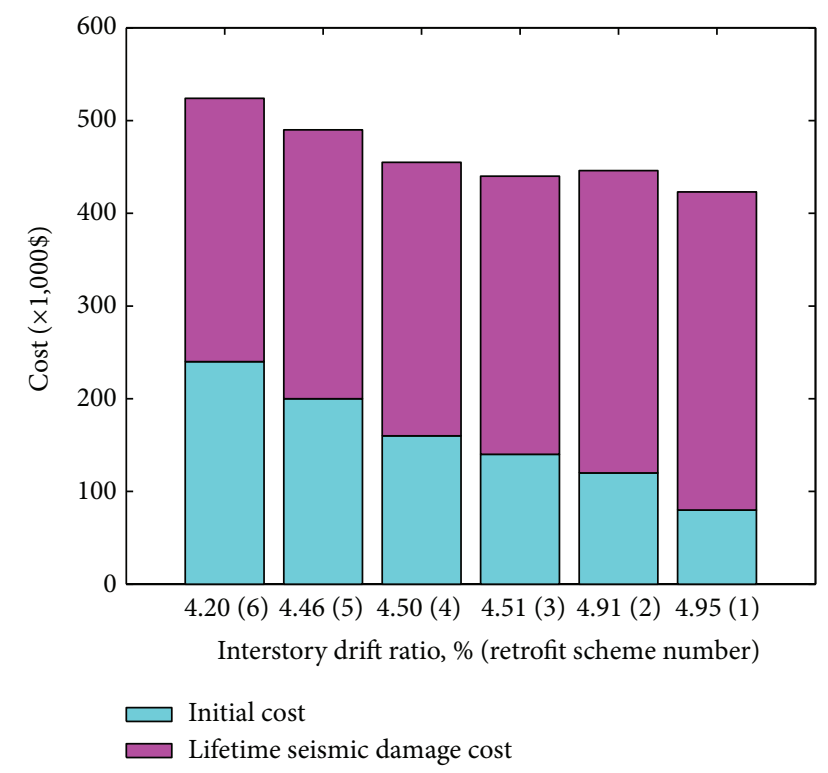

FIGURE 10: Results of the optimal retrofit schemes of the three-story SMRF.

the total cost and initial cost may be altered according to the seismic retrofit unit cost; that is, a decrease in the retrofit unit cost results in a decrease in the initial cost, and thus, the total cost may be governed by the lifetime seismic damage cost. Furthermore, if a different evaluation method for the lifetime seismic damage cost is employed, the total cost might change and yield different results. Therefore, the relationship between each cost (e.g., initial cost, lifetime seismic damage cost, and total cost) and the structural performance can vary depending on the employed retrofit method (i.e., unit cost for retrofitting), which is related to the initial cost.

Figure 12 presents the pushover curve obtained from a nonlinear static analysis of the three retrofit schemes (schemes 1, 3, and 6) and the existing structure. As the initial cost increases, the maximum strength increases and the postpeak behavior characterized by the strength degrading feature is also improved. The energy dissipation capacities of the retrofit schemes in Table 3, which might be considered as another structural performance index, were calculated from the pushover curves. It is confirmed that increasing the initial retrofit cost tends to increase the energy dissipation capacity as well. However, unlike the interstory drift ratio, the highest initial cost does not result in the largest energy dissipation, which was obtained from retrofit scheme 4 .

5.2. Nine-Story Building. In the nine-story example, seismic retrofitting also employed performance-based seismic engineering; as in the three-story example, the seismic performance was evaluated subject to the $P$ performance objective. As a result of the seismic performance evaluation of the nine-story example in relation to performance objective $P$, it is indicated that the maximum interstory drift ratio was $5.71 \%$, which exceeded the allowable interstory drift ratio of 5\% in FEMA 356 for CP, as shown in Figure 13. In this example, seismic retrofitting was also required to meet the performance objective. Therefore, the proposed multiobjective optimization seismic retrofit method was applied to the nine-story building example.

Seven Pareto solutions were obtained; each solution denotes a single optimal retrofit plan. Table 4 summarizes the retrofit locations and numbers, initial retrofit costs, and lifetime seismic damage costs of each Pareto solution.

The initial retrofit cost was calculated in the same manner as in the three-story example. The interstory drift ratio of each retrofit plan is presented in Figure 11. All seven Pareto retrofit plans satisfied the 5\% allowable interstory drift ratio for CP.

Figure 14 presents the relationship between the initial retrofit cost, lifetime seismic damage cost, total cost, and seismic performance of the Pareto solutions. In the ninestory example, increasing the initial retrofit cost generally decreases the lifetime seismic damage cost and improves the seismic performance. However, unlike the three-story building, the highest initial cost (scheme number 4) does not yield the smallest interstory drift ratio (scheme number 6). Figure 15 illustrates the same relationship as the threestory building case, in which the initial cost is inversely proportional to the lifetime seismic damage cost and the total cost is proportional to the initial cost.

Figure 16 presents a pushover curve obtained from the nonlinear static analysis of the three retrofit plans and existing frame. The energy dissipation capacities calculated from the pushover curves are proportional to the initial costs; the highest initial cost generates the highest energy dissipation in scheme 7. This proportional relationship between the initial cost and energy dissipation capacity was not observed in the three-story building case.

From the results obtained from the three- and ninestory examples, for rational decision-making on seismic retrofitting strategy, the costs (e.g., initial retrofit cost, lifetime seismic damage cost, and total cost) and seismic performances (e.g., interstory drift ratio and energy dissipation capacity) of each Pareto solution should be assessed holistically. A retrofit scheme can be selected from the optimized solutions by considering the retrofit target building's condition, the building owner's demands, and other situations. That is, the best retrofit strategy or most effective retrofit scheme can vary depending on various situations (e.g., decision maker's preference, building condition, and retrofit unit cost). Therefore, it is desirable to provide several retrofit strategies from which the decision makers can select. A more rational decision regarding the seismic retrofit of an existing structure can be made by assessing not only the cost associated with the early stages of retrofit but also the postretrofit life-cycle cost of the structure and the improved seismic performance.

\section{Conclusions}

This study proposes a performance-based multiobjective optimization seismic retrofit method for steel momentresisting frames. The connection retrofit method was chosen among seismic retrofit methods for steel moment-resisting frames, and the proposed method develops seismic retrofit schemes for the location and number of connections that 
TABLE 4: Optimal retrofit scheme of the nine-story SMRF for performance objective $P$.

\begin{tabular}{|c|c|c|c|c|c|c|c|c|}
\hline & Before & Scheme 1 & Scheme 2 & Scheme 3 & Scheme 4 & Scheme 5 & Scheme 6 & Scheme 7 \\
\hline $\begin{array}{l}\text { Number of retrofit } \\
\text { connections }\end{array}$ & 0 & 23 & 30 & 40 & 47 & 50 & 58 & 79 \\
\hline Retrofit location & - & $\begin{array}{c}\text { X1, X8-9 } \\
\text { X23, X25 } \\
\text { X28-29 } \\
\text { X41, X45 } \\
\text { X48, X51 } \\
\text { X55, X62 } \\
\text { X64, X67 } \\
\text { X71, X73 } \\
\text { X76-77 } \\
\text { X81, X83 } \\
\text { X86-87 }\end{array}$ & $\begin{array}{c}\text { X2-3, X14 } \\
\text { X18-19 } \\
\text { X21, X24 } \\
\text { X32, X34 } \\
\text { X37, X40 } \\
\text { X46, X47 } \\
\text { X52 X55-59 } \\
\text { X62, X67 } \\
\text { X69 X70-72 } \\
\text { X74, X78 } \\
\text { X81 } \\
\text { X86-87 }\end{array}$ & $\begin{array}{c}\text { X3, X7, X11 } \\
\text { X19-21 } \\
\text { X23-24 } \\
\text { X28 } \\
\text { X30-34 } \\
\text { X36-38 } \\
\text { X44, X48 } \\
\text { X51-X52 } \\
\text { X54 X56-57 } \\
\text { X64-66 } \\
\text { X68, X71 } \\
\text { X75 X77-80 } \\
\text { X82-86 } \\
\text { X90 }\end{array}$ & $\begin{array}{c}\text { X2-4, X7 } \\
\text { X11, X13 } \\
\text { X17 X21-22 } \\
\text { X25-27 } \\
\text { X29-32 } \\
\text { X34, X36 } \\
\text { X38-40 } \\
\text { X42-43 } \\
\text { X47-51 } \\
\text { X54-X56 } \\
\text { X58, X60 } \\
\text { X62, X65 } \\
\text { X69 X71-73 } \\
\text { X75-76 } \\
\text { X78, X80 } \\
\text { X83-84 } \\
\text { X86-88 }\end{array}$ & $\begin{array}{c}\text { X1, X4 X8-12 } \\
\text { X14, X16 } \\
\text { X20 X23-24 } \\
\text { X26, X29 } \\
\text { X32-37 } \\
\text { X39, X42 } \\
\text { X45-49 } \\
\text { X53, X55 } \\
\text { X57 X60-61 } \\
\text { X63-65 } \\
\text { X67, X69 } \\
\text { X71-72 } \\
\text { X74-75 } \\
\text { X78 X80-82 } \\
\text { X86-90 }\end{array}$ & $\begin{array}{c}\text { X1, X3-6 } \\
\text { X8-X10 } \\
\text { X15, X18 } \\
\text { X20, X22 } \\
\text { X24-28 } \\
\text { X31-X35X41- } \\
\text { X44X46-47 } \\
\text { X49- } \\
\text { X52X54- } \\
\text { X57X59- } \\
\text { X60X63- } \\
\text { X66X68-70 } \\
\text { X72 } \\
\text { X75- } \\
\text { X77X79-84 } \\
\text { X86 } \\
\text { X88-89 }\end{array}$ & $\begin{array}{c}\mathrm{X} 1 \\
\mathrm{X} 3-13 \\
\mathrm{X} 15-21 \\
\mathrm{X} 24-33 \\
\mathrm{X} 35-37 \\
\mathrm{X} 39-46 \\
\mathrm{X} 49-62 \\
\mathrm{X} 65-79 \\
\mathrm{X} 81-90\end{array}$ \\
\hline $\begin{array}{l}\text { Initial retrofit cost } \\
\text { (thousand dollars) }\end{array}$ & 0 & 460 & 600 & 800 & 940 & 1,000 & 1,160 & 1,580 \\
\hline $\begin{array}{l}\text { Lifetime seismic } \\
\text { damage cost } \\
\text { (thousand dollars) }\end{array}$ & 1,839 & 1,505 & 1,327 & 1,164 & 1,147 & 1,093 & 1,077 & 1,041 \\
\hline $\begin{array}{l}\text { Maximum } \\
\text { interstory drift } \\
\text { ratio (\%) }\end{array}$ & 5.71 & 4.82 & 4.48 & 4.12 & 4.26 & 4.06 & 4.01 & 4.23 \\
\hline $\begin{array}{l}\text { Dissipated energy } \\
(\mathrm{kN} \cdot \mathrm{m})\end{array}$ & $3,522.71$ & $4,304.61$ & $4,424.63$ & $4,814.29$ & $4,931.91$ & $5,022.90$ & $5,125.60$ & $5,716.21$ \\
\hline
\end{tabular}

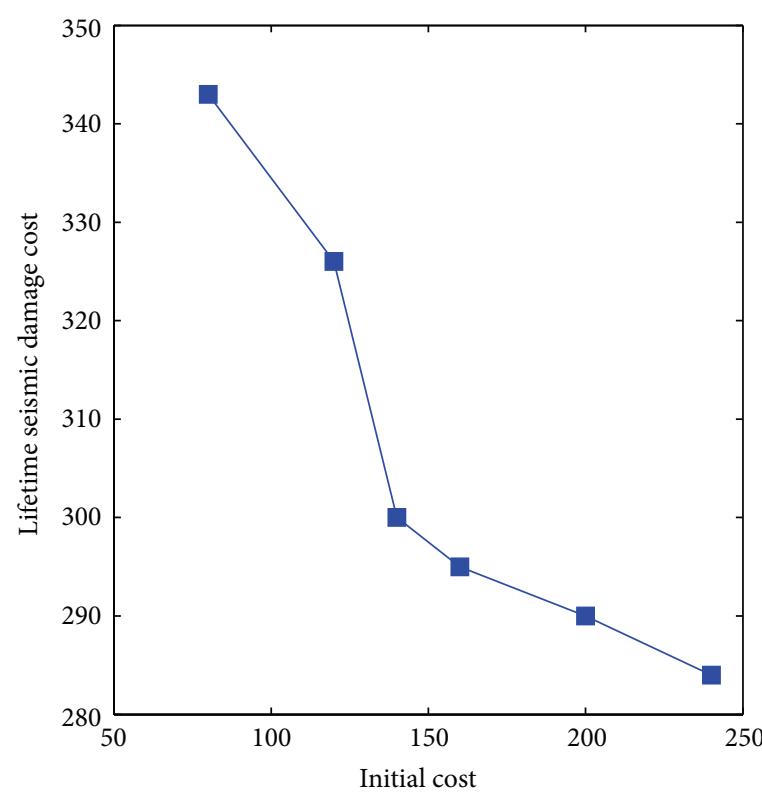

(a) Initial cost versus lifetime seismic damage cost

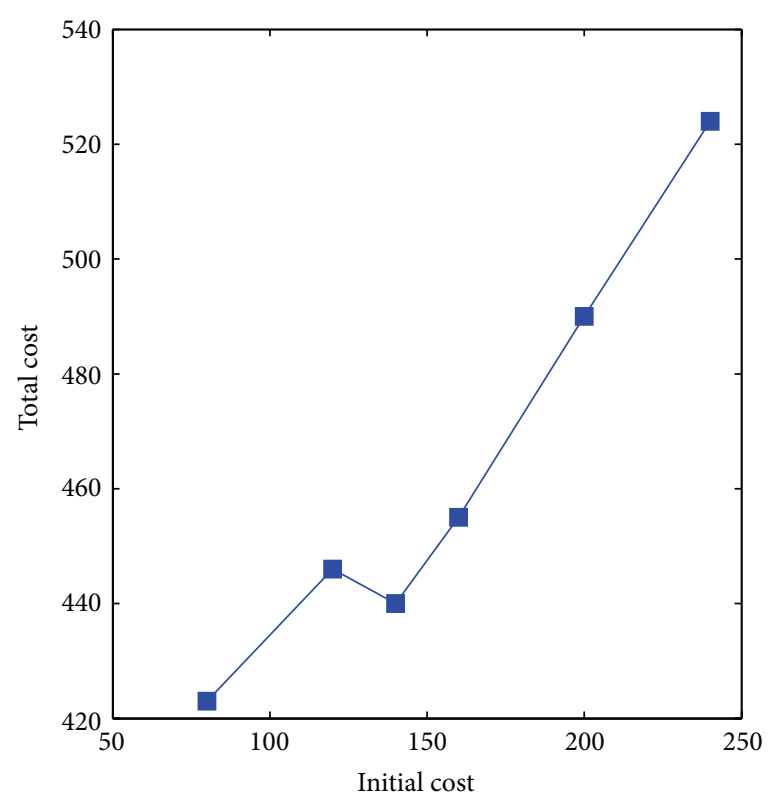

(b) Initial cost versus total cost

FIGURE 11: Relationship between the costs. 


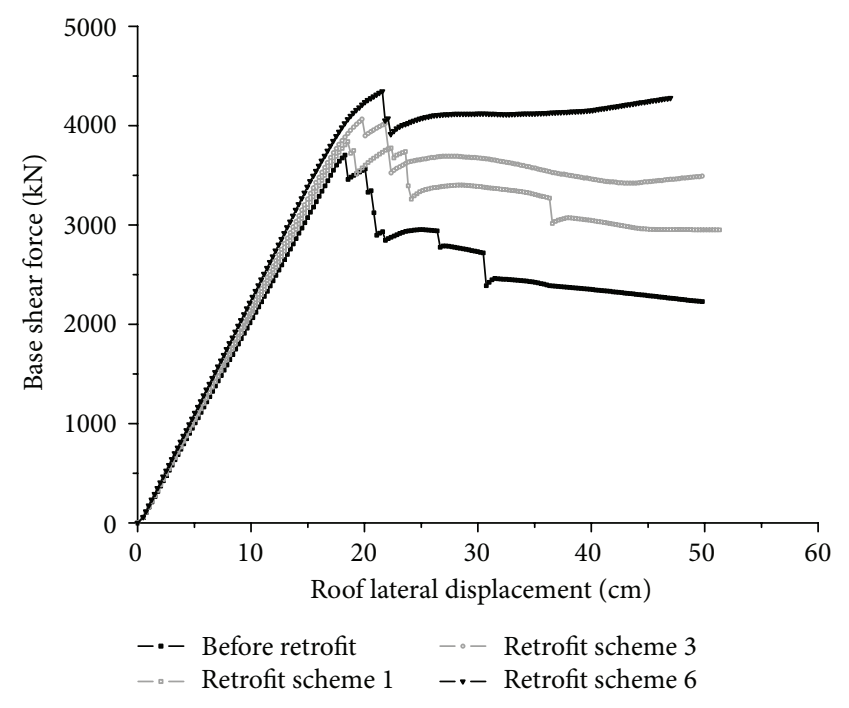

Figure 12: Pushover curves of the existing and retrofitted threestory SMRF.

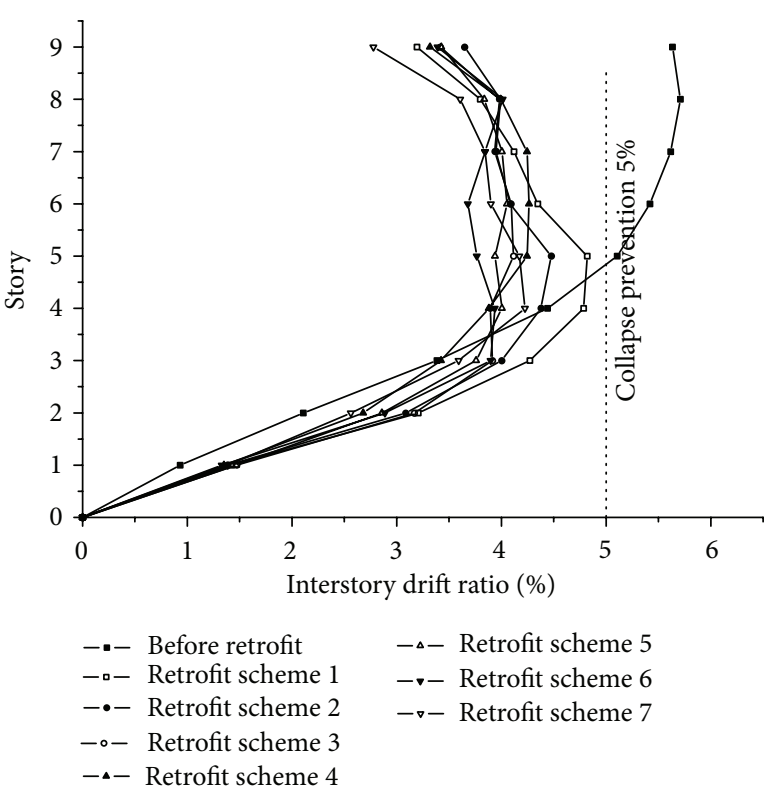

FIGURE 13: Interstory drift ratio of the existing and retrofitted ninestory SMRF.

need to be retrofitted. NSGA-II was applied to solve the multiobjective optimization problem. As objective functions, the initial cost for the connection retrofit and the lifetime seismic damage cost are selected, and a seismic performance level below the $5 \%$ interstory drift ratio was employed as a constraint condition.

The proposed seismic retrofit optimization method was applied to SAC benchmark three- and nine-story examples and provided seismic retrofit schemes that minimize the initial retrofit cost and the lifetime seismic damage cost after retrofit while satisfying specific seismic performance

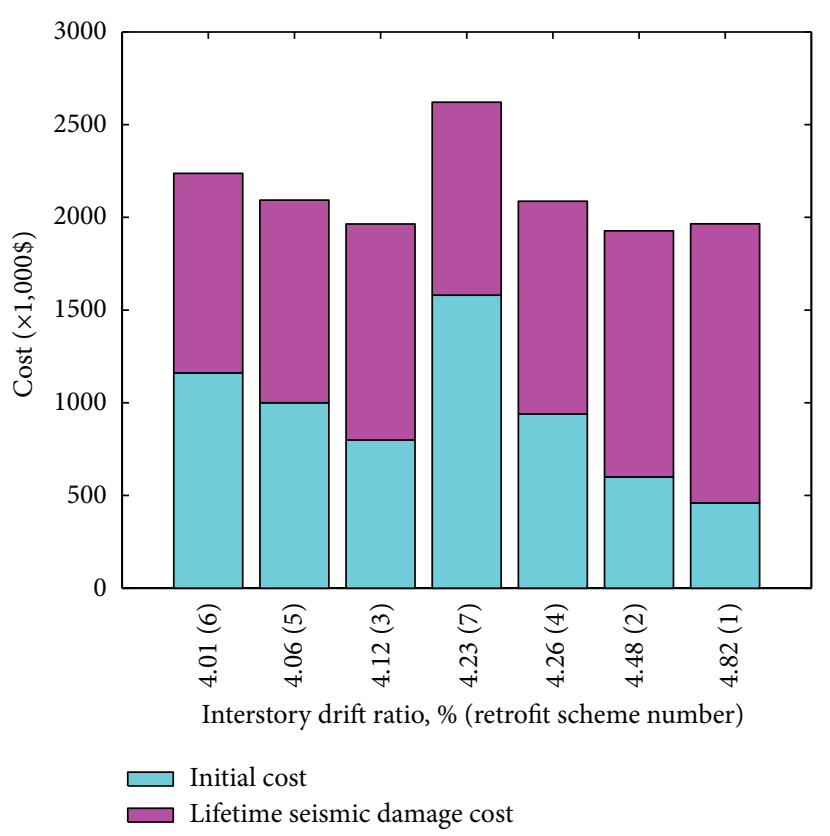

FIGURE 14: Result of the optimal retrofit schemes of the nine-story SMRF.

objectives, such as the interstory drift ratio. Various Pareto optimal solutions were obtained for each example. The Pareto solutions demonstrated that the lifetime seismic damage cost decreased as the initial retrofit cost increased. Although every Pareto solution existed within a seismic performance boundary set by a constraint function, the seismic performance tended to increase with the initial retrofit cost. From these results, it can be expected that the building owner is subjected to increased seismic damage costs that may be generated after retrofit if seismic retrofitting is selected only considering the low initial retrofit cost, resulting in low seismic performance. This result also indicates that the high initial cost assures high structural performance, which results in a low lifetime seismic damage cost.

The total life-cycle cost, which is the sum of the initial and lifetime seismic damage cost, provides other options for the decision maker to decide on a retrofit method. From the Pareto solutions obtained from the examples, the total life-cycle cost is governed by the initial cost, which is relatively high compared to the lifetime seismic damage cost. However, the life-cycle cost, which is adopted in most existing optimization procedures, is strongly dependent on the initial unit cost for retrofit or the evaluation method for the lifetime seismic damage cost.

This method allows for retrofit schemes based on a rational economic assessment that considers not only the initial retrofit cost but also the lifetime seismic damage cost of a structure. Furthermore, the total life-cycle cost can be a useful index for the decision maker of the retrofit method.

Therefore, instead of being limited to only one factor, all costs (e.g., initial cost, the lifetime seismic damage cost, and total cost) and seismic performances (e.g., interstory drift 


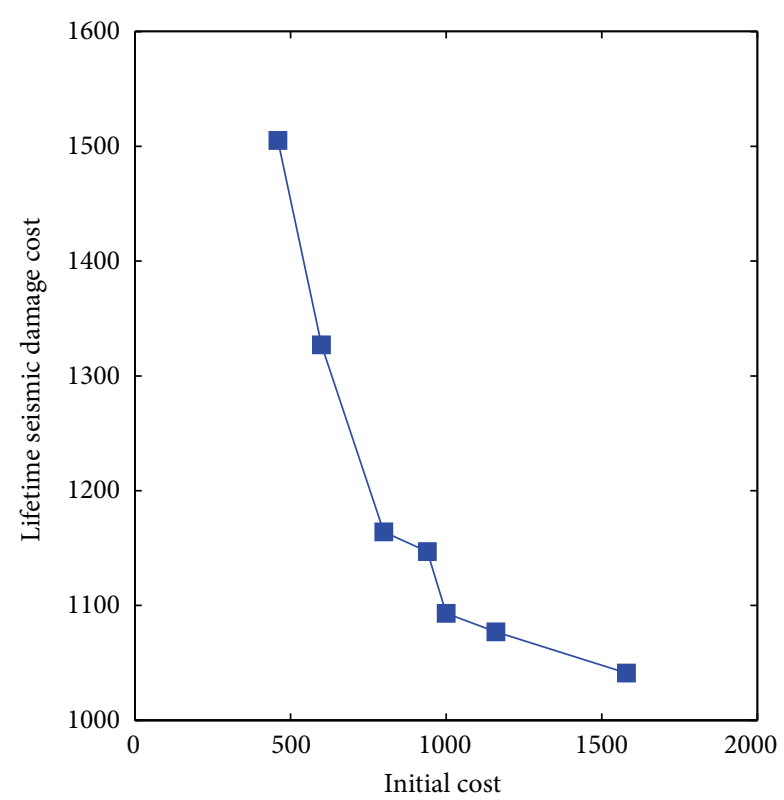

(a) Initial cost versus lifetime seismic damage cost

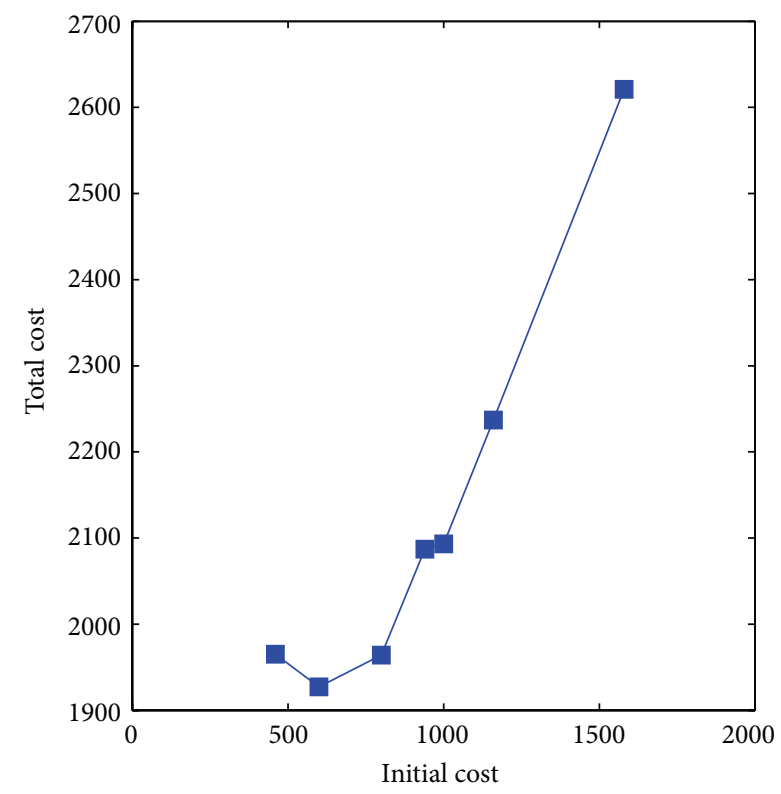

(b) Initial cost versus total cost

FIGURE 15: Relationship between the costs.

ratio and energy dissipating capacity) must be considered simultaneously when choosing a seismic retrofit plan, which allows a building owner to make a decision with a wide range of proposed seismic retrofit schemes based on a rational economical assessment.

\section{Conflict of Interests}

The authors declare that there is no conflict of interests regarding the publication of this paper.

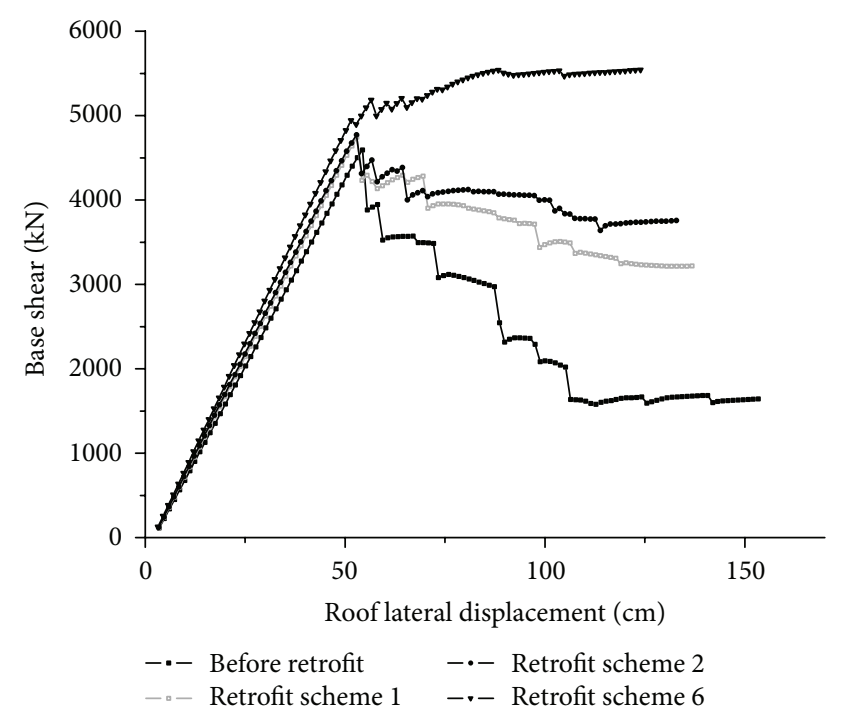

FIGURE 16: Pushover curves of the existing and retrofitted nine-story SMRF.

\section{Acknowledgments}

This work was supported by the National Research Foundation of Korea (NRF) Grant (no. 2011-0018360) funded by the Korea Government (Ministry of Science, ICT and Future Planning (MSIP)).

\section{References}

[1] S. Hussain, P. Van Benschoten, A. Nerurkar, M. Al Satari, and T. Guttema Viscous, "Fluid damper retrofit of pre-northridge steel moment frame structures," in Proceedings of the 75th SEAOC Annual Convention, Long Beach, Calif, USA, 2006.

[2] C. Ash and S. Bartoletti, "Seismic rehabilitation of an existing braced frame hospital building by direct replacement with buckling-restrained braces," in Proceedings of the ATC and SEI Conference on Improving the Seismic Performance of Existing Buildings and Other Structures, pp. 68-74, December 2009.

[3] W. Liu, J. D. Givens, R. Kanitkar, and C. Blaney, "Seismic evaluation and rehabilitation of a three story pre-northridge steel frame essential service facility," in Proceedings of the ATC and SEI Conference on Improving the Seismic Performance of Existing Buildings and Other Structures, pp. 56-67, December 2009.

[4] I. J. Malley, M. Sinclair, T. Graf et al., "Seismic upgrade of a 15-story steel moment frame building-satisfying performance criteria with application of experimental and analytical procedures," in Proceedings of the ATC and SEI Conference on Improving the Seismic Performance of Existing Buildings and Other Structures, pp. 75-84, December 2009.

[5] E. Aydin and M. H. Boduroglu, "Optimal placement of steel diagonal braces for upgrading the seismic capacity of existing structures and its comparison with optimal dampers," Journal of Constructional Steel Research, vol. 64, no. 1, pp. 72-86, 2008.

[6] T. Hagishita and M. Ohsaki, "Optimal placement of braces for steel frames with semi-rigid joints by scatter search," Computers and Structures, vol. 86, no. 21-22, pp. 1983-1993, 2008. 
[7] B. K. Oh, Optimization for performance-based seismic retrofit of existing steel moment resisting frames using connection upgrade [thesis], University of Yonsei, 2011.

[8] Y. J. Kang and Y. K. Wen, "Minimum life-cycle cost structural design against natural hazards," Structural Research Series 629, Department of Civil and Environmental Engineering, University of Illinois at Urbana-Champaign, Urbana, Ill, USA, 2000.

[9] M. Kohno and K. R. Collins, "Merging life cycle cost analysis and performance-based design," in Proceedings of the 8th ASCE Specialty Conference on Probabilistic Mechanics and Structural Reliability, 2000.

[10] M. Liu, S. A. Burns, and Y. K. Wen, "Optimal seismic design of steel frame buildings based on life cycle cost considerations," Earthquake Engineering and Structural Dynamics, vol. 32, no. 9, pp. 1313-1332, 2003.

[11] M. Liu, Y. K. Wen, and S. A. Burns, "Life cycle cost oriented seismic design optimization of steel moment frame structures with risk-taking preference," Engineering Structures, vol. 26, no. 10, pp. 1407-1421, 2004.

[12] M. Fragiadakis, N. D. Lagaros, and M. Papadrakakis, "Performance-based multiobjective optimum design of steel structures considering life-cycle cost," Structural and Multidisciplinary Optimization, vol. 32, no. 1, pp. 1-11, 2006.

[13] F. Jalayer, D. Asprone, A. Prota, and G. Manfredi, "Multi-hazard upgrade decision making for critical infrastructure based on life-cycle cost criteria," Earthquake Engineering and Structural Dynamics, vol. 40, no. 10, pp. 1163-1179, 2011.

[14] J. E. Padgett, K. Dennemann, and J. Ghosh, "Risk-based seismic life-cycle cost-benefit (LCC-B) analysis for bridge retrofit assessment," Structural Safety, vol. 32, no. 3, pp. 165-173, 2010.

[15] "Recommended seismic evaluation and upgrade criteria for existing welded steel moment-frame buildings," Tech. Rep. FEMA 351, Federal Emergency Management Agency, Washington, DC, USA, 2000.

[16] AISC/NIST, Modification of Existing Welded Steel Moment Frame Connections for Seismic Resistance, vol. 12 of Steel Design Guide Series, American Institute of Steel Construction, Chicago, Ill, USA, 1999.

[17] B. Chi, C.-M. Uang, and A. Chen, "Seismic rehabilitation of preNorthridge steel moment connections: a case study," Journal of Constructional Steel Research, vol. 62, no. 8, pp. 783-792, 2006.

[18] J. M. Ricles, C. Mao, L.-W. Lu, and J. W. Fisher, "Inelastic cyclic testing of welded unreinforced moment connections," Journal of Structural Engineering, vol. 128, no. 4, pp. 429-440, 2002.

[19] S. W. Han, G. U. Kwon, and K. H. Moon, "Cyclic behaviour of post-Northridge WUF-B connections," Journal of Constructional Steel Research, vol. 63, no. 3, pp. 365-374, 2007.

[20] K. Deb, A. Pratap, S. Agarwal, and T. Meyarivan, "A fast and elitist multiobjective genetic algorithm: NSGA-II," IEEE Transactions on Evolutionary Computation, vol. 6, no. 2, pp. 182197, 2002.

[21] S. W. Choi and H. S. Park, "Multi-objective seismic design method for ensuring beam-hinging mechanism in steel frames," Journal of Constructional Steel Research, vol. 74, pp. 17-25, 2012.

[22] K. A. De Jong, An analysis of the behavior of a class of genetic adaptive systems [Ph.D. thesis], University of Michigan, 1975.

[23] D. E. Goldberg, Genetic Algorithms in Search, Optimization and Machine Learning, Addison-Wesley, Reading, Mass, USA, 1989.

[24] "Prestandard and commentary for the seismic rehabilitation of buildings," Tech. Rep. FEMA 356, Federal Emergency Management Agency, Washington, DC, USA, 2000.
[25] S. Shi, Evaluation of connection fracture and hysteresis type on the seismic response of steel buildings [thesis], University of Illinois, Urbana, Ill, USA, 1997.

[26] A. Gupta and H. Krawinkler, "Seismic demands for performance evaluation of steel moment resisting frame structures," Tech. Rep. 132, The John A. Blume Earthquake Engineering Center, Stanford University, 1999.

[27] K. Lee and D. A. Foutch, "Seismic performance evaluation of pre-Northridge steel frame buildings with brittle connections," Journal of Structural Engineering, vol. 128, no. 4, pp. 546-555, 2002.

[28] B. Stojadinović, S. C. Goel, K.-H. Lee, A. G. Margarian, and J.-H. Choi, "Parametric tests on unreinforced steel moment connections," Journal of Structural Engineering, vol. 126, no. 1, pp. 40-49, 2000.

[29] Pacific Earthquake Engineering Research Center, http://opensees.berkeley.edu.

[30] "The state-of art report on performance prediction and evaluation of steel moment-frame buildings," Tech. Rep. FEMA 355f, Federal Emergency Management Agency, Washington, DC, USA, 2000.

[31] "Recommended seismic design criteria for new steel momentframe buildings," Tech. Rep. FEMA 350, Federal Emergency Management Agency, Washington, DC, USA, 2000.

[32] L. T. Kien, K. Lee, J. Lee, and D. H. Lee, "Seismic demand evaluation of steel MRF buildings with simple and detailed connection models," International Journal of Steel Structures, vol. 10, no. 1, pp. 15-34, 2010.

[33] K. H. Lee and D. A. Foutch, "Performance prediction and evaluation of special moment frame buildings for seismic loads," SAC Background Document SAC/BD-00/25, SAC Joint Venture, 2000. 


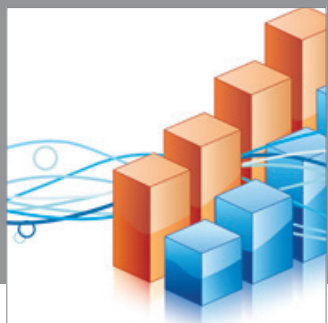

Advances in

Operations Research

mansans

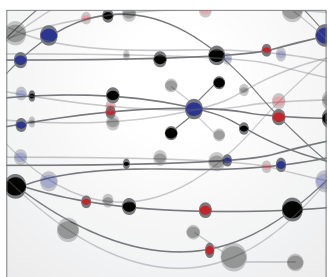

The Scientific World Journal
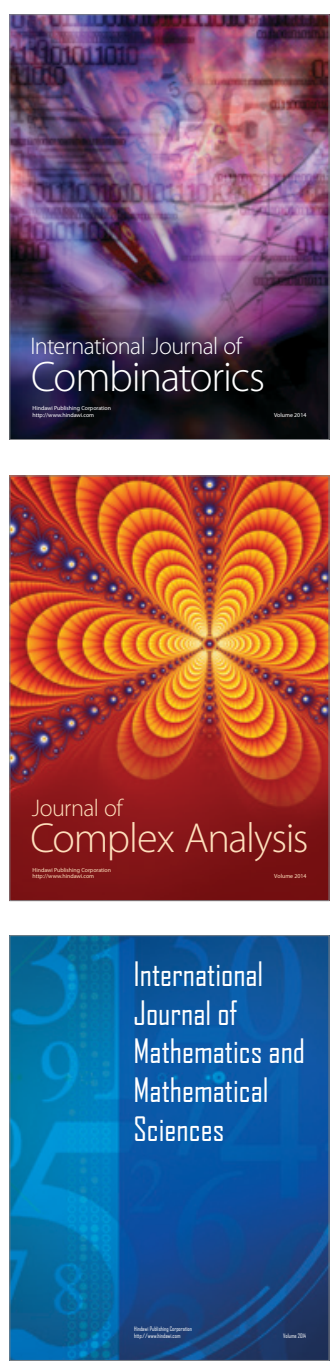
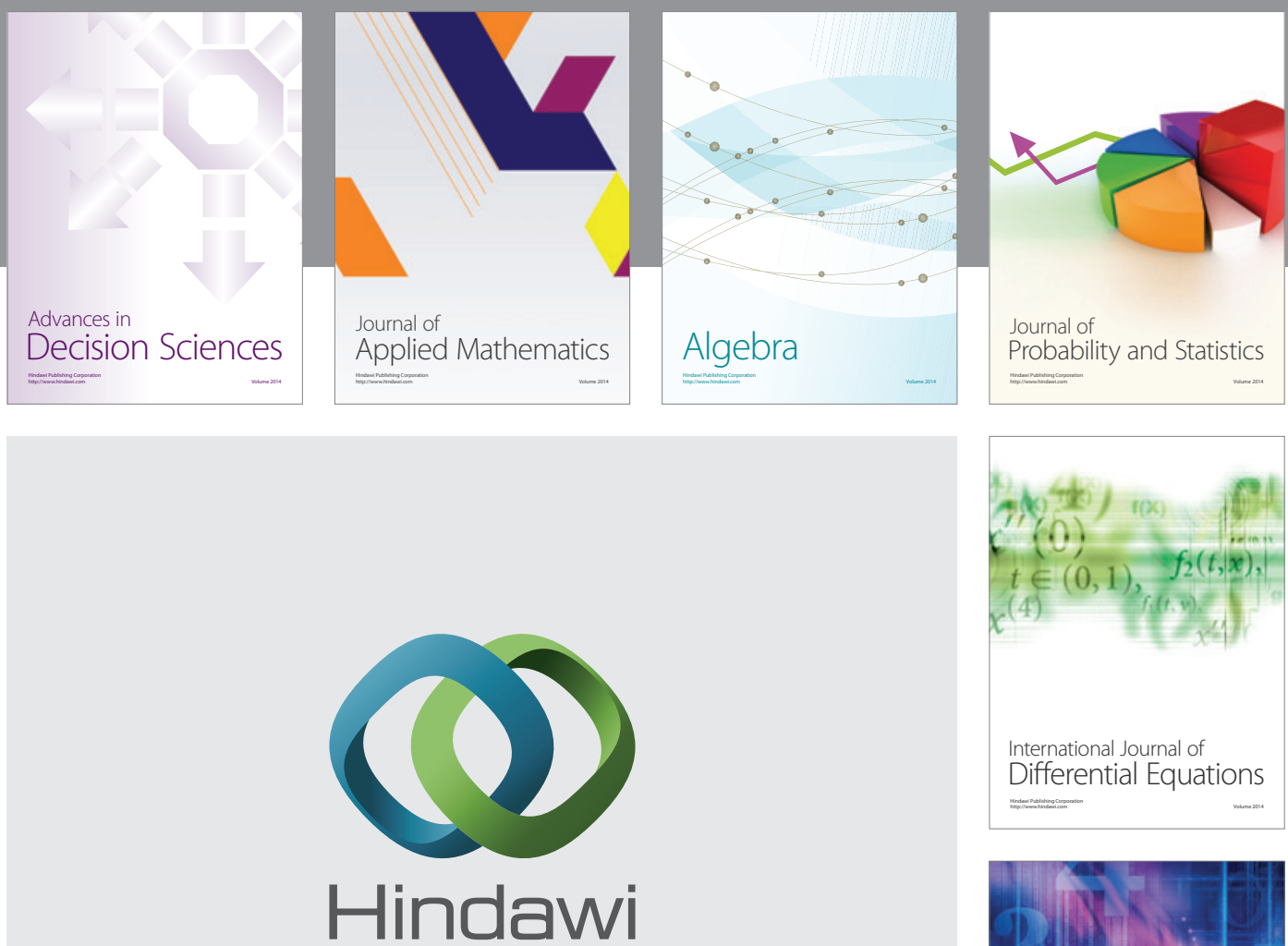

Submit your manuscripts at http://www.hindawi.com
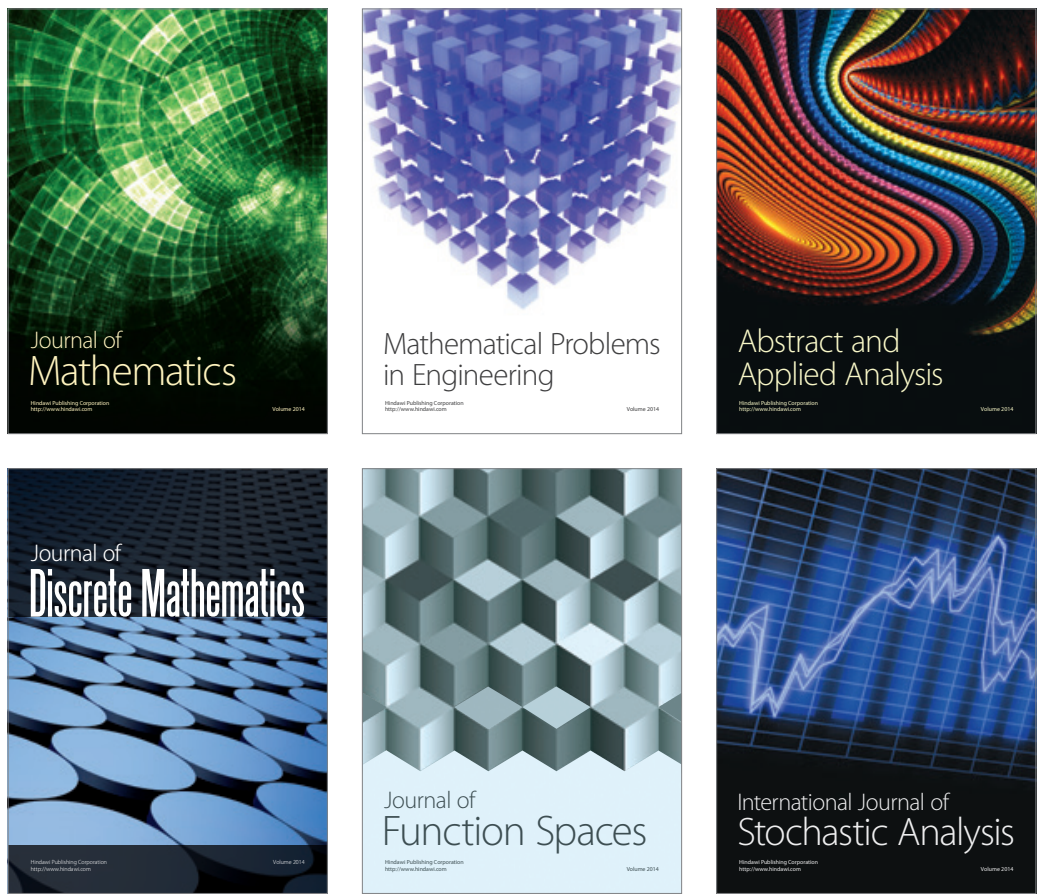

Journal of

Function Spaces

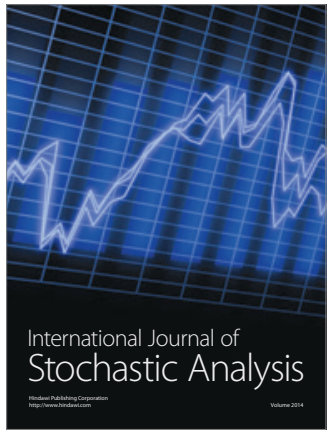

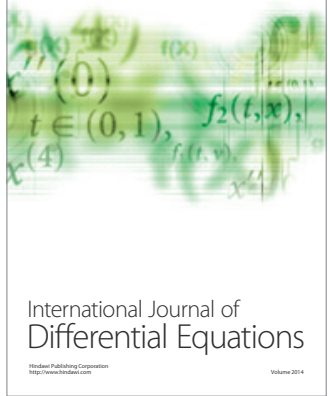
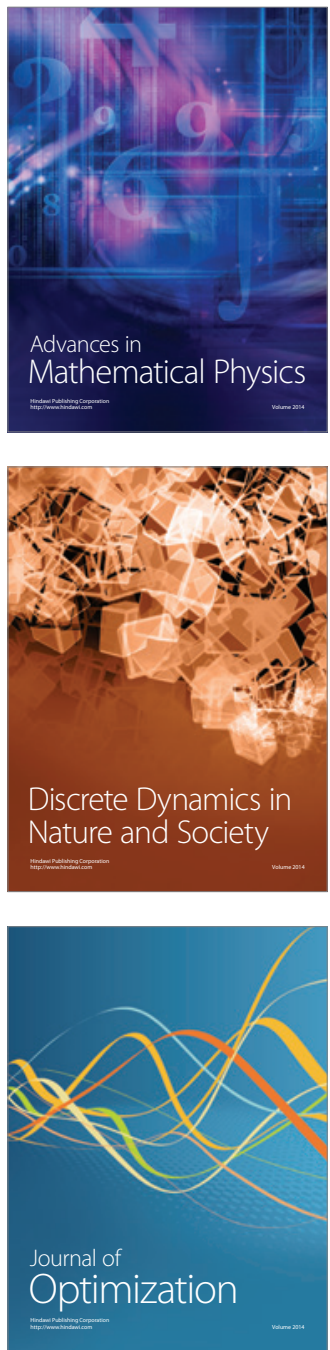